\title{
Shakedown, ratcheting and fatigue analysis of cathode coating in lithium-ion battery under steady charging-discharging process
}

\author{
Ying Chen ${ }^{1}$, Haofeng Chen ${ }^{1,2 *}$, Weiling Luan ${ }^{*}$ \\ ${ }^{1}$ Key Laboratory of Pressure Systems and Safety (DOE), School of Mechanical \\ and Power Engineering, East China University of Science and Technology, Shanghai, \\ 200237, China \\ ${ }^{2}$ Department of Mechanical \& Aerospace Engineering, University of \\ Strathclyde, Glasgow, G1 1XJ, UK \\ *Email: haofeng.chen@strath.ac.uk; luan@ecust.edu.cn
}

\begin{abstract}
The cyclic plasticity behaviour and failure mechanism of the cathode material in lithium-ion batteries urgently need to be understood due to the cyclic lithium-ion diffusion-induced stress during charging-discharging process. Many researches have focused on the shakedown and ratcheting responses of lithium-ion battery anode. However, the systematic investigation on the plasticity behaviour of lithium-ion battery cathode is still lacking. In this paper, the cyclic plasticity behaviour of $\mathrm{LiNi}_{\mathrm{x}} \mathrm{Mn}_{\mathrm{y}} \mathrm{Co}_{\mathrm{z}} \mathrm{O}_{2}$ electrode subjected to cyclic lithiation/delithiation under a constant mechanical load is investigated comprehensively. The shakedown, ratcheting and fatigue analyses of active layer are conducted using direct numerical techniques based on the Linear Matching Method framework, while coin cell electrochemical experiments are performed simultaneously to support the analysis. The effect of thickness of coating on the shakedown and ratcheting response is investigated, and the thickness is confirmed
\end{abstract}


as a crucial parameter that can influence the battery performance. The strain-fatigue life curve is also obtained to effectively predict the life of active coating. Moreover, the numerical results reveal the existence of low cycle fatigue at the centre, and ratcheting mechanism on the edge of the cathode, which is consistent well with the experimental result.

Keywords: Lithium-ion battery; Electrode; Diffusion-induced stress; Shakedown; Ratcheting; Fatigue

\section{Introduction}

Lithium-ion batteries are privileged choice for the powering various application of electrification of automotive transportation and renewable energies due to their high energy density and longevity $[1,2]$. The basis of lithium-ion battery operation is the result of cyclic insertion and extraction of lithium ions from electrodes. As lithium ions intercalate into and out of the electrode, a field of stress known as diffusion-induced stress occurs, and the presence of such stress in the active material is a direct cause of mechanical failure because of the massive volumetric deformation. Furthermore, the stress within electrodes can also affect the diffusion process and cause persistent loss of capacity of batteries in the long-term cycles[3].

Following the approach proposed by Prussin[4], the evolution of diffusioninduced stress in the electrochemical active particle and thin film during the chargingdischarging process has been extensively investigated by researchers. For instance, a one-dimensional model was employed by Huggins and Nix[5] to analyse the fracture 
mechanism of the particle. A coupled diffusion-stress model was presented by Christensen and Newman[6], and used to calculate the stress in spherical active particles. In their work, they highlighted the pressure-diffusion effect and high lithiumion concentration. Zhang et al.[7] presented a set of numerical simulations of intercalation-induced stresses in ellipsoidal $\mathrm{LiMn}_{2} \mathrm{O}_{4}$ particles when subjected to galvanostatic lithium insertion and extraction. These obtained results suggested that particles with smaller sizes and larger aspect ratios were preferred for the stress reduction. A cohesive model was developed by Bhandakkar et al.[8] to study the crack nucleation in an initially crack-free strip electrode under galvanostatic chargingdischarging process, which confirmed the existence of a critical characteristic dimension to prevent crack nucleation. Haftbaradaran et al.[9] indicated the surface locking instability in a cylindrical electrode by coupling the analyses of internal stresses and activation energy needed for diffusion. These researches focus on the elastic stress and deformation, and the effects of plasticity on electrode are lacking of attentions.

When the electrode is subjected to continuous operating charging-discharging loading, cyclic plasticity behaviour such as shakedown, ratcheting and fatigue can occur to the structure. Specifically, shakedown behaviour can be further classified into elastic shakedown and plastic shakedown behaviour (alternating plasticity). Plastic yielding of materials under cyclic loadings is necessary for ratcheting and fatigue to occur with extensive plastic flow related to the charging-discharging process[10, 11]. Individually, ratcheting can induce incremental plastic collapse of electrode materials due to the accumulation of plastic deformation, while fatigue can lead to local crack initiation and 
propagation.

For the cycle life of electrode materials, the understanding of cyclic plasticity is crucial as it enables deformation while limiting the stress level and can cause mechanical fatigue. Dislocations are generated by the solute lattice contraction stresses, and this indicates the plastic behavior of the electrode material[12, 13]. It is demonstrated that the electrode deforms plastically per cycle through the in situ experimental analysis of stress in silicon thin-film electrodes during continuous charging-discharging process[14]. Plastic flow is likely to significantly accelerate the damage to the electrode, which is consistent with the work reported by Sethuraman et al.[15], whereby energy dissipated in the plastic flow could be a significant fraction of the total energy loss in the cell. As such, it is of great significance to account for cyclic plastic behaviour in the electrode materials. Zhao et al.[16] investigated a particle of silicon anode subjected to cyclic lithiation and delithiation in three types of behaviour observed: elasticity, cyclic plasticity and the plastic shakedown behaviour. Jia and Li[17] investigated the failure mechanisms associated with the wrinkling of a thin film electrode on a compliant substrate, and it was revealed that ratcheting induced necking and cracking at wrinkling troughs of the thin film electrode. Guo et al.[18] found thin film island electrode with mechanical properties dependent on the lithium concentration, naturally undergoes plastic ratcheting with accumulative deformation and failure during cyclic charging and discharging process. By considering the contribution of diffusion and convection of lithium ions to the plastic flow of electrode material, Li et al.[19] revealed the increase in compressive Cauchy stress in the Silicon electrode with the 
increase in boundary flux. However, the researches are all about the cyclic plasticity behaviour such as shakedown and ratcheting for anode materials, especially for silicon, impact of diffusion-induced plasticity on the cyclic behaviour of cathode materials is still not well understood.

$\mathrm{LiNi}_{\mathrm{x}} \mathrm{Mn}_{\mathrm{y}} \mathrm{Co}_{\mathrm{z}} \mathrm{O}_{2}$ (NMC) is one of the most promising cathode materials in the development of next-generation Li-ion battery, due to its high energy density and cost effectiveness[20]. In this paper, shakedown, ratchet and fatigue analyses of NMC active layer are performed by using the Linear Matching Method (LMM)[21-26], which provides an efficient way to solve the cyclic structural responses of nonlinear materials by a number of iterative linear analyses. Detailed analyses on NMC coating subjected to a constant pressure and lithiation/delithiation cycling are conducted based on the coin cell configuration for the charging-discharging experiments. The effects of the thickness of NMC coating on the shakedown and ratcheting boundaries are also studied for the use of thick electrodes to increase the energy density of battery recently[27, 28]. The failure mechanisms including ratcheting and low cycle fatigue are then systematically investigated by the numerical results and experimental observation. The strain-fatigue life curve is further obtained to predict the damage life of NMC coating.

\section{Experimental test}

In the preparation of NMC cathode, $80 \mathrm{wt} \% \mathrm{LiNi}_{5} \mathrm{Mn}_{3} \mathrm{Co}_{2} \mathrm{O}_{2}(\mathrm{NMC532})$ active particles, $10 \mathrm{wt} \%$ polyvinylidene fluoride (PVDF), and 10\% carbon black are mixed in $\mathrm{N}$-methyl-2-pyrrolidone solvent to form a homogenous slurry. After that, the slurry is 
coated on to a current collector ( $\mathrm{Al}$ foil). The thickness of active material coating on $\mathrm{Al}$ current is about $20 \mu \mathrm{m}$ thick with a loading density of $2.7 \mathrm{mg} / \mathrm{cm}^{2}$. To remove the volatile solvent and moisture, the as-coated electrode is dried in a vacuum oven overnight at $120^{\circ} \mathrm{C}$, and it is later stored in argon-filled glovebox (with moisture and oxygen levels less than $0.5 \mathrm{ppm}$ ). Before the assembly of CR-2025 type coin cell, the as-prepared electrode is firstly cut into circular disc with $12 \mathrm{~mm}$ in diameter, then used in the assembly of coin cells in the argon-filled glovebox for further electrochemical investigation, as shown in Fig.1d. NMC electrode, Li foil, and Celgard-2500 membrane are used as cathode, anode, and separator, respectively. The electrolyte used in this work is composed of $1 \mathrm{M} \mathrm{LiPF}_{6}$ salt dissolved in a mixed ethylene carbonate/diethyl carbonate solvent with 1:1 volume ratio. To ensure the complete wetting of the electrode prior to electrochemical tests, all assembled cells are rested overnight. Cyclic tests are then designed to investigate the effects of cycle numbers and charging rates on the mechanical properties of NMC particles. The electrochemical performances of assembled coin cells are evaluated by Land Cell System (CT2001A, Wuhan Jinnuo Electronic Co. Ltd, Wuhan China). The cells are cycled between 2.8 and $4.3 \mathrm{~V} v s . \mathrm{Li} / \mathrm{Li}^{+}$ via a VSP potentiostat at charging rate of $0.5 \mathrm{C}, 1 \mathrm{C}(1 \mathrm{C}=160 \mathrm{~mA} / \mathrm{g}), 2 \mathrm{C}$ and $3 \mathrm{C}$. The coin cells (at charged state of $4.3 \mathrm{~V}$ ) are later disassembled in the glovebox, and the NMC electrodes are collected for characterizations. 

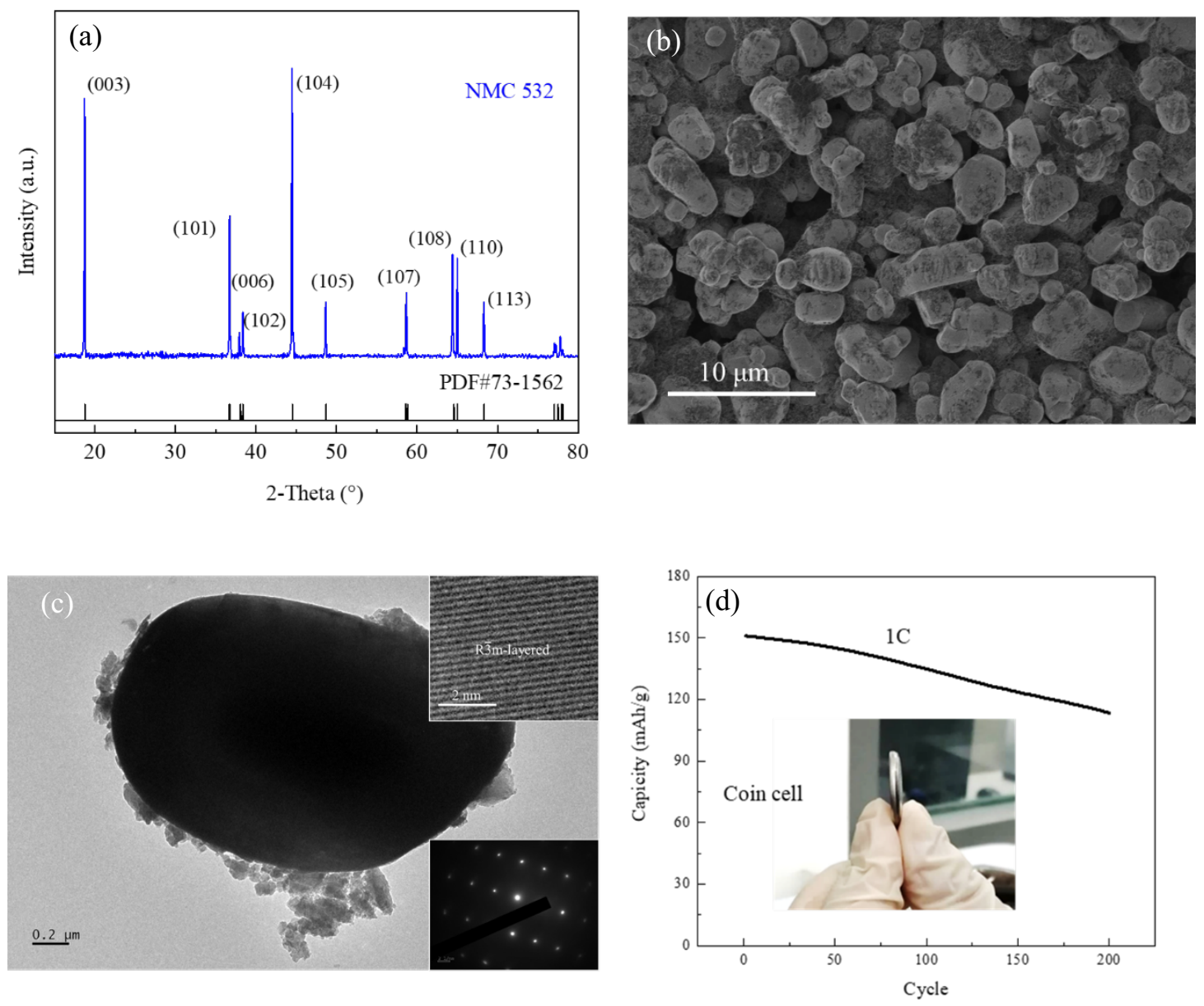

Figure 1 (a) XRD pattern of NMC cathode material (b) SEM images of NMC

cathode microstructure (c) HRTEM images and SAED pattern of NMC active particle

(d) Electrochemical performance of NMC/Li half-cell at 1C at 2.8-4.3 voltage

windows

The X-ray diffraction (XRD) pattern of pristine cathode material is collected using a Rigaka D/max2250 X-ray diffractometer equipped with $\mathrm{Cu}$ Ka radiation. All peaks of $\mathrm{NMC}$ cathode material in XRD patterns can be indexed to the layered $\alpha-\mathrm{NaFeO}_{2}-$ type structure with space group $\mathrm{R} \overline{3} \mathrm{~m}$ (PDF\#87-1562), as shown in Fig.1a. To study the morphology and microstructure of the pristine NMC cathode, scanning electron microscopy (SEM, Hitachi S4300) and transmission electron microscopy (TEM, JEOL 
JEM 2100) images are collected, whereby a particle size of $\sim 3 \mu \mathrm{m}$ is noted. The inset in Fig.1c shows the high-resolution TEM (HRTEM) image and the selected area electron diffraction (SAED) result of NMC active particle, indicating the hexagonal layered structure for the as-prepared single-crystal NMC particles. Figure 1d shows the discharge capacity plot at the charging rate of $1 \mathrm{C}$ within a potential window of $2.8-4.3$ $\mathrm{V} v s . \mathrm{Li} / \mathrm{Li}^{+}$. It is noted that the capacity of the cell decays almost linearly with cycle numbers.

\section{Numerical procedures}

\subsection{Evaluation of lithium-ion diffusion-induced elastic stresses}

The finite element (FE) code ABAQUS[29] is employed in the simulation of the lithium-ion diffusion-induced stresses, with analogy to thermal stress[4]. In order to facilitate the diffusion-stress coupling, the equivalent heat equation is solved and a sequentially coupled heat-stress analysis is performed, as ABAQUS is conveniently configurated for such procedure.

The total strain including the elastic strain $\dot{\varepsilon}_{i j}^{e}$, and the diffusion-induced strain $\dot{\varepsilon}_{i j}^{d}$ are written as:

$$
\dot{\varepsilon}_{i j}=\dot{\varepsilon}_{i j}^{e}+\dot{\varepsilon}_{i j}^{d}
$$

The elastic strain $\dot{\varepsilon}_{i j}^{e}$ follows Hooke's law, according to the following equation:

$$
\dot{\varepsilon}_{i j}^{e}=\frac{1}{E}\left[(1+v) \dot{\sigma}_{i j}-v \dot{\sigma}_{k k} \delta_{i j}\right]
$$

where $E$ is Young's modulus, $v$ is Poisson's ratio, $\delta_{i j}$ is Kronecher symbol. The diffusion strain rate can be expressed with the expansion coefficient due to the insertion and extraction of lithium ions as follows:

$$
\dot{\varepsilon}_{i j}^{d}=\beta_{i j} \dot{c}
$$


For heat flow, the heat equation follows the physical laws of heat conduction and conservation of energy:

$$
k \frac{\partial u}{\partial t}+\nabla q=\varnothing
$$

where $k$ is the thermal conductivity which combines thermal diffusivity, density, and specific heat (commonly denoted as $k=\alpha \rho c_{s}$ ), $u$ refers to the temperature, $t$ is time, $q$ is the heat flux that describes the flow of energy per unit area at per unit time, and $\varnothing$ is defined as internal heat source.

For diffusion process, the principle of mass conservation can be written in the following form:

$$
\frac{\partial c}{\partial t}+\nabla J=0
$$

where $c$ is the concentration of diffusion component (lithium ions), and $J$ refers to the diffusion flux which measures the amount of substance flowing through a unit area at a unit time interval. When assuming $u=c, \phi=0, q=J$ and $k=1$, mass diffusion behaviour can be analogized as heat conduction process[30].

Based on the classical Fick's first law, an expression of flux in the absence of stress effects can result in the following equation:

$$
J=-D_{f} \nabla c
$$

where $D_{f}$ is the diffusion coefficient, and it can be expressed as:

$$
D_{f}=D_{0} \exp \left(\frac{\Omega \sigma_{h}}{R T}\right)
$$

where $D_{0}$ is the stress-free diffusivity, $\Omega$ refers to the partial molar volume of lithiumion, $R$ is the gas constant, $T$ is the absolute temperature, and $\sigma_{\mathrm{h}}$ represents the hydrostatic stress which corresponds to the diffusion-induced stress.

The diffusivity $D_{f}$, related to the diffusion process can be embedded in the stress 
effect, with boundary condition as shown below:

$$
J=-D_{f}\left(\nabla c-\frac{\Omega c}{R T} \nabla \sigma_{h}\right)=\frac{i_{n}}{F}
$$

where $i_{n}$ is the current density on the electrode surface (with the assumption that current density is constant), and F is Faraday's constant.

By developing a set of USDFLD-UMATHT subroutines, the above mentioned formula can be achieved in ABAQUS[29] to perform coupled diffusion-stress analysis, as verified in our previous work[31]. The lithium-ion diffusion-induced stresses would then be used to evaluate the shakedown, ratchet boundaries and low cycle fatigue life of NMC cathode material.

\subsection{Numerical procedures for shakedown, ratchet and fatigue analysis}

To obtain the shakedown limit and ratcheting boundary of the cathode material subjected to a cyclic lithium-ion diffusion flux under a constant mechanical load, the LMM is adopted, and it is a direct method and consists of a number of iterative linear analyses with the spatial and time variation of modulus to simulate nonlinear material responses. The procedures of performing LMM in the calculation of shakedown and ratchet limit of structure were demonstrated in the previous work[22, 23]. The numerical procedures are briefly summarized in this section.

Consider an elastic-perfectly plastic structure with volume $V$, and surface area $S$, which satisfies the von-Mises yield criterion. The structure is subjected to diffusion flux $\lambda_{D} D\left(x_{i}, t\right)$ within $V$, mechanical loads $\lambda_{p} P\left(x_{i}, t\right)$ over a part of the surface area $S_{T}$, which applied over a time period of $0 \leq t \leq \Delta t$. On the remaining surface $S_{R}$, zero displacement rate condition is constrained. The linear elastic stress solution of the structure can be expressed as: 


$$
\hat{\sigma}_{i j}(x, t)=\lambda_{p} \hat{\sigma}_{i j}^{P}(x, t)+\lambda_{D} \hat{\sigma}_{i j}^{D}(x, t)
$$

where $\hat{\sigma}_{i j}^{P}(x, t)$ is the linear elastic stress solution of the mechanical load $P\left(x_{i}, t\right)$, $\hat{\sigma}_{i j}^{D}(x, t)$ is the linear elastic stress solution of the diffusion flux $D\left(x_{i}, t\right)$.

When the stress and strain rates asymptote to a cyclic state as follows:

$$
\sigma_{i j}(t)=\sigma_{i j}(t+\Delta t), \dot{\varepsilon}_{i j}(t)=\dot{\varepsilon}_{i j}(t+\Delta t)
$$

the general stress solution for the cyclic issue can be defined as:

$$
\sigma_{i j}(x, t)=\lambda \hat{\sigma}_{i j}(x, t)+\bar{\rho}_{i j}(x)+\rho_{i j}^{r}(x, t)
$$

where $\bar{\rho}_{i j}(x)$ is the constant residual stress in equilibrium with no surface traction occurring on $S_{T}$, which corresponds to the residual stress field at the beginning and end of a cycle, $\rho_{i j}^{r}(x, t)$ is the changing residual stress during a cycle, and $\lambda$ is the load parameter.

\subsubsection{Shakedown analysis}

For the shakedown process[22], the changing residual stress $\rho_{i j}^{r}(x, t)=0$. The cyclic stress history is denoted as:

$$
\sigma_{i j}(x, t)=\lambda \hat{\sigma}_{i j}(x, t)+\bar{\rho}_{i j}(x)
$$

Based on Koiter's theorem[32], the shakedown upper bound multiplier $\lambda_{S D}^{U B}$ can be given by the following equation:

$$
\lambda_{S D}^{U B}=\frac{\int_{V}\left[\sigma_{y} \sum_{n=1}^{N} \bar{\varepsilon}\left(\Delta \varepsilon_{i j}^{n}\right)\right] d V}{\int_{V}\left[\sum_{n=1}^{N} \widehat{\sigma}_{i j}\left(t_{n}\right) \Delta \varepsilon_{i j}^{n}\right] d V}
$$

where $\sigma_{y}$ is the von Mises yield stress, $\Delta \varepsilon_{i j}^{n}$ is the increment of strain at time $t_{n}$ and $\bar{\varepsilon}$ is the effective strain $\left(\bar{\varepsilon}=\sqrt{\frac{2}{3} \Delta \varepsilon_{i j}^{n} \Delta \varepsilon_{i j}^{n}}\right)$. As $\lambda_{S D}^{U B}$ is calculated based on upper bound theorem so the least multiplier satisfies $\lambda_{S D}^{U B} \geq \lambda_{S D}$, where $\lambda_{S D}$ is the exact shakedown limit. 


\subsubsection{Direct steady cycle analysis for the evaluation of plastic strain range and} varying residual stress field

When the applied cyclic load is greater than the shakedown limit, the history of the changing residual stress field associated with the applied cyclic diffusion flux, and the corresponding plastic strain ranges for the low cycle fatigue assessment can be calculated using the direct steady cycle analysis (DSCA)[23]. It is worth noting that the evaluation of the varying residual stress field by the DSCA is also the first step in the ratcheting boundary analysis.

The varying residual stress $\Delta \rho_{i j}{ }_{M}^{k}$, is first calculated for the $n$th load instance at the $m$ th iteration cycle, where $n=1,2,3, \ldots, N$ and $m=1,2,3, \ldots, M$. When the convergence occurs at the $M$ th cycle of iterations, the summation of changing residual stresses is satisfied $\sum_{n=1}^{N} \Delta \rho_{i j} \stackrel{n}{M}=0$ due to the stable cyclic response. The constant residual stress can be calculated by:

$$
\bar{\rho}_{i j}=\sum_{n=1}^{N} \Delta \rho_{i j_{1}}^{n}+\sum_{n=1}^{N} \Delta \rho_{i j_{2}}^{n}+\sum_{n=1}^{N} \Delta \rho_{i j_{3}}^{n}+\cdots+\sum_{n=1}^{N} \Delta \rho_{i j_{M}}^{n}
$$

The magnitude of plastic strain occurring at time $t_{n}$ can then be determined by:

$$
\Delta \varepsilon_{i j}^{P}\left(t_{n}\right)=\frac{1}{2 \bar{\mu}^{n}}\left(\hat{\sigma}_{i j}^{\prime}\left(t_{n}\right)+\rho_{i j}^{\prime}\left(t_{n}\right)\right)
$$

where $\bar{\mu}^{n}$ is the iterative shear modulus, and $\rho_{i j}^{\prime}\left(t_{n}\right)$ is the converged accumulated residual stress at time $t_{n}$, with the following equation:

$$
\rho_{i j}\left(t_{n}\right)=\bar{\rho}_{i j}^{0}+\sum_{k=1}^{n} \Delta \rho_{i j} \stackrel{k}{M}
$$

\subsubsection{Ratcheting Analysis}

The history of the residual stress calculated based on the DSCA algorithm and the linear elastic solution are used as inputs for the evaluation of ratchet limit. 


$$
\hat{\sigma}_{i j}=\lambda \hat{\sigma}_{i j}^{\bar{F}}+\hat{\sigma}_{i j}^{\Delta}\left(x_{k}, t\right)+\rho_{i j}(x, t)
$$

where $\lambda$ is a load multiplier, $\hat{\sigma}_{i j}^{\bar{F}}$ is the constant elastic stress, and $\hat{\sigma}_{i j}^{\Delta}\left(x_{k}, t\right)$ is the cyclic elastic stress.

The ratchet limit analysis considers the constant residual stress $\bar{\rho}_{i j}(x)$ and the changing residual stress $\rho_{i j}(x, t)$ during a cycle. The upper bound ratchet limit multiplier $\lambda_{R C}^{U B}$ can be computed as:

$$
\lambda_{R C}^{U B}=\frac{\int_{V} \sum_{k=1}^{K} \sigma_{y} \bar{\varepsilon}\left(\Delta \varepsilon_{i j}^{k}\right) d V-\int_{V}\left[\sum_{k=1}^{K} \widehat{\sigma}_{i j}^{\Delta}\left(t_{k}\right)+\rho_{i j}\left(t_{k}\right)\right] \Delta \varepsilon_{i j}^{k} d V}{\int_{V} \widehat{\sigma}_{i j}^{\bar{F}} \sum_{k=1}^{K} \Delta \varepsilon_{i j}^{k} d V}
$$

where $\bar{\varepsilon}\left(\Delta \varepsilon_{i j}^{k}\right)=\sqrt{\frac{2}{3} \Delta \varepsilon_{i j}^{k} \Delta \varepsilon_{i j}^{k}}$ and $\Delta \varepsilon_{i j}^{k}$ is the increment of strain that occurs at $t_{k}$, and $\rho_{i j}\left(t_{k}\right)$ is the residual stress at $t_{k} . \lambda_{R C}^{U B}$ denotes the endurance capacity of the body subjected to the additional constant load $\hat{\sigma}_{i j}^{\bar{F}}$ without incurring ratchetting behavior. Based on the iterative procedure, LMM calculates the least upper bound limit for the ratchet limit.

\section{Finite Element Modelling}

The schematic illustration of the lithium-ion interaction/deintercalation in electrode during charging-discharging process is presented in Fig.2a. According to the realistic charging-discharging experiment, the thickness of both the NMC coating layer and $\mathrm{Al}$ current collector is taken as $20 \mu \mathrm{m}$, with a diameter of $12 \mathrm{~mm}$. The NMC cathode is then subjected to cycling lithiation/delithiation at a charging rate of $1 \mathrm{C}$. Due to the thin film geometry of the cathode, a finite element model of electrode with $100 \mu \mathrm{m}$ diameter, $20 \mu \mathrm{m}$ thickness is constructed to provide a better analysis into the lithiumion diffusion-induced-stresses along the thickness direction. In order to determine the thickness effect to the shakedown and ratcheting limits of the NMC cathode material, 
$10 \mu \mathrm{m}$ and $30 \mu \mathrm{m}$ thickness of NMC cathode models are also analysed. Using lithiation process as an example (Fig.2b), flux $J$ (Eq.8) is applied on the top surface which demonstrates the insertion of lithium-ion into the surface. This is related to the given current density of $5.43 \mathrm{~A} / \mathrm{m}^{2}$ in the coin cell electrochemical experiment. Although the Al current collector has an impact on the cyclic plastic behaviour, a simplified FE model without $\mathrm{Al}$ current collector but considering full constraints on the bottom surface of active layer is adopted to produce conservative results, since the Young's modulus of the $\mathrm{Al}$ current collector is much greater than the Young's modulus of NMC active layer. The electrode structure is then meshed with C3D20RT for coupled diffusion stress analysis and C3D20R for cyclic plasticity analysis.

(a)

Cathode material

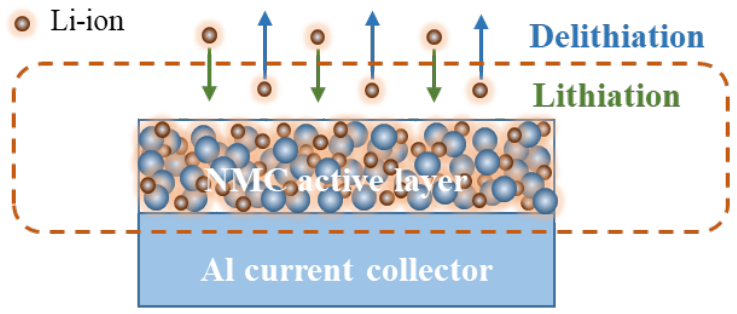

(b)

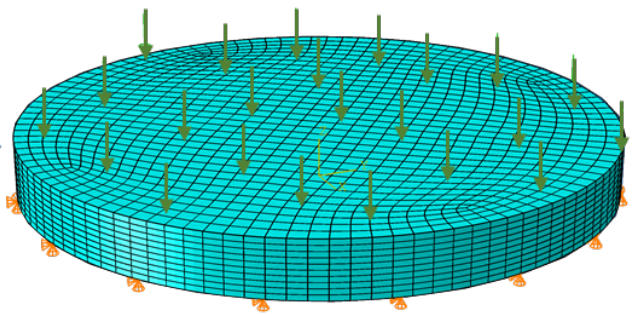

Figure 2 (a)Schematic illustration of electrode during lithiation/delithiation process, whereby NMC active layer is coated on the Al current collector (sectional viewer) (b) Boundary condition and the load applied to electrode during lithiation

$$
\text { stage used in ABAQUS }
$$

Table 1 Material properties of NMC cathode for numerical analysis

\begin{tabular}{cccccc}
\hline Thickness & Young's modulus & Poisson's & Diffusivity & Partial molar volume & Yield stress \\
$(\mu \mathrm{m})$ & $E(\mathrm{GPa})$ & ratio $v$ & $D\left(\mathrm{~m}^{2} / \mathrm{s}\right)$ & $\left(\mathrm{m}^{3} / \mathrm{mol}\right)$ & $\sigma_{y}(\mathrm{MPa})$ \\
\hline $10,20,30$ & $6.5[33]$ & $0.3[34]$ & $10^{-15}[35]$ & $2.1 \times 10^{6}[36]$ & 100 \\
\hline
\end{tabular}


Based on the previous studies, the electrode coating is assumed to be isotropic and modelled as an elastic-perfectly plastic material[31, 37-40] due to the insignificant material hardening during the charging-discharging process [41]. The key properties of the material are listed in Table 1. Due to the complicated compositions in cathode material, there is a lack of accurate yield stress value of NMC532 active layer in the published reference. Therefore, an assumed but reasonable value of $100 \mathrm{MPa}$ is taken in this work.

\section{Results and discussion}

\subsection{Linear elastic finite element analysis of NMC coating}

Prior to the shakedown, ratcheting and fatigue analyses, the linear elastic finite element analyses are firstly conducted to obtain the fictitious elastic stress fields. Figure 3 shows the von Mises stress distribution in NMC cathode material with $20 \mu \mathrm{m}$ in thickness, that is undergoing a steady charging-discharging cycle at the charging rate of $1 \mathrm{C}$. The duration of a charging-discharging cycle for NMC cathode is $7200 \mathrm{~s}$, with an individual duration of charging and discharging process to $3600 \mathrm{~s}$ each. Therefore, the charging-discharging stage at A: 0 s, B: $1025 \mathrm{~s}, \mathrm{C}: 3600 \mathrm{~s}$ and D: $4025 \mathrm{~s}$ are selected. Figure 3a shows the overall view of the diffusion-induced stress distribution in cathode material. Fig. $3 \mathrm{~b}$ focuses on the diffusion-induced stress along the thickness direction from the centre of cathode, while a path is created from the centre of the top surface to the bottom of the NMC coating (Fig.4). It can be observed that the diffusion-induced stress in cathode material varies mainly at the top surface, which is the interface of the cathode and electrolyte. In contrast, for the surface close to the current collector, the 
stress effect becomes less significant. The diffusion induced stress at the top surface of cathode is much higher than that at the bottom surface of cathode. Using the centre integration point at the top surface of NMC cathode, the diffusion-induced stress and its corresponding lithium-ion concentration with cycling duration are presented in Fig.5(a). It is assumed that the minimum value of lithium-ion concentration in the NMC active layer is 0 during an electrochemical cycle. During the charging (delithiation) process, the von Mises stress in the NMC active layer increases initially and it subsequently decreases. It is noted that the lithium-ion concentration decreases with cycling time. As the lithium ions continuously intercalate into the NMC active plate, the lithiated region tends to expand, while the unlithiated region and the Al current collector tend to remain undeformed. Hence, compressive stress is generated in these active plates due to the volume limitation that is restricted by the current collector.

To systematically illustrate the linear elastic stress evolution and the related lithium-ion variation in the $\mathrm{NMC}$ active layer at the charging rate of $1 \mathrm{C}$ during a steady electrochemical cycle, the relationship along the thickness path at the chargingdischarging stage of A: 0 s, B: 1025 s, C: 3600 s and D: 4025 s are presented in Fig.5(b) and Fig.5(c) respectively, which are plotted with respect to Fig.4. In a steady delithiation and lithiation process, the time intervals with the greatest changes in the diffusion-induced stress and lithium-ion concentration are the initial charging stage A and the initial discharging stage $\mathrm{C}$. It is worth noting that the variations of the von Mises stress and lithium-ion concentration mainly occur close to the top surface of cathode, while negligible changes are observed at the area close to the bottom. These results are 
due to the instantaneous change of the diffusion flux direction, with the intercalation and deintercalation of lithium-ion occurring at the top surface of the cathode that is in direct contact with the electrolyte.

(a)

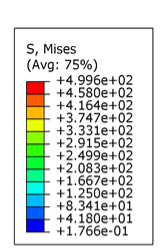

A: Charging begins, $0 \mathrm{~s}$
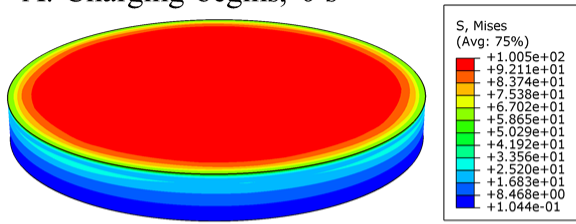

B: Charging process, $1025 \mathrm{~s}$

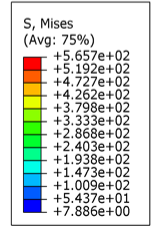

C: Discharging begins, $3600 \mathrm{~s}$
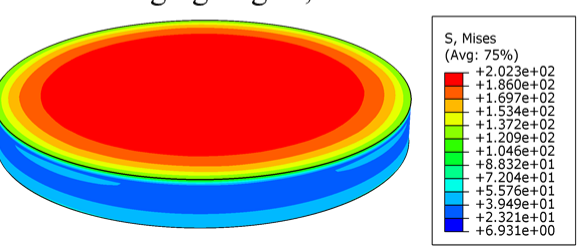

D: Discharging process, $4025 \mathrm{~s}$

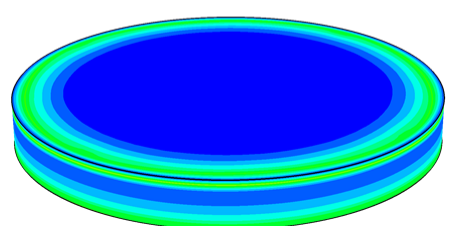

(b)

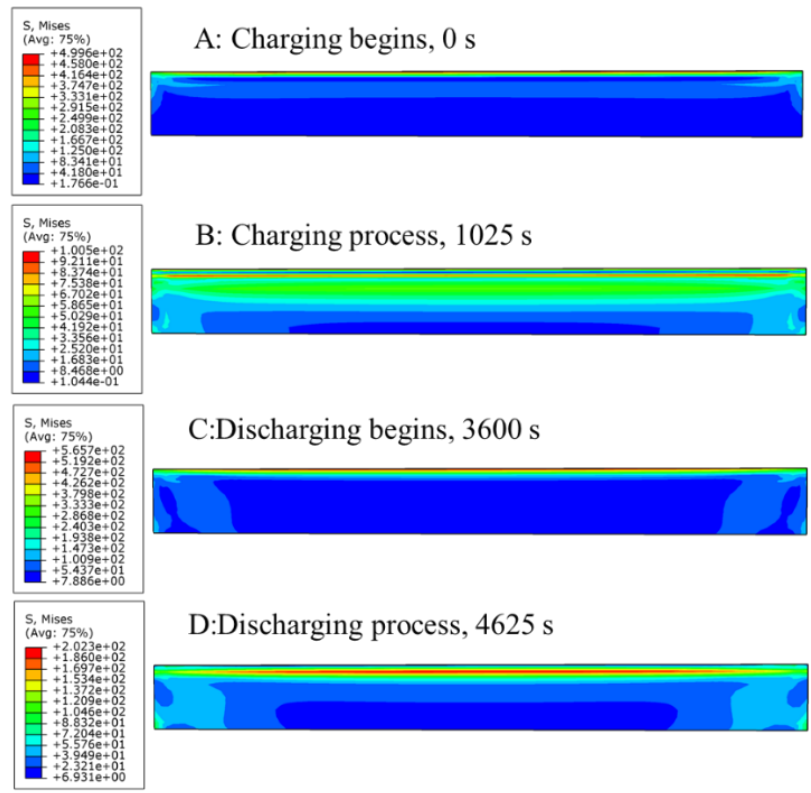

Figure $3 \mathrm{NMC}$ active layer with $20 \mu \mathrm{m}$ in thickness at the charging rate of $1 \mathrm{C}$ during a steady charging-discharging cycle (a) Overall contour map of von Mises stress a selected charging-discharging stage (b) Contour map of von Mises stress along the thickness path at selected charging-discharging stage, A: charging begins at $0 \mathrm{~s}, \mathrm{~B}$ : charging process at $1025 \mathrm{~s}, \mathrm{C}$ : discharging begins at $3600 \mathrm{~s}$ and D: discharging 


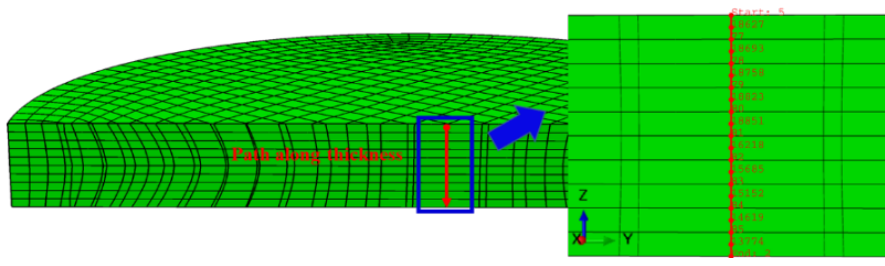

Figure 4 Definition of path along the thickness of NMC active layer
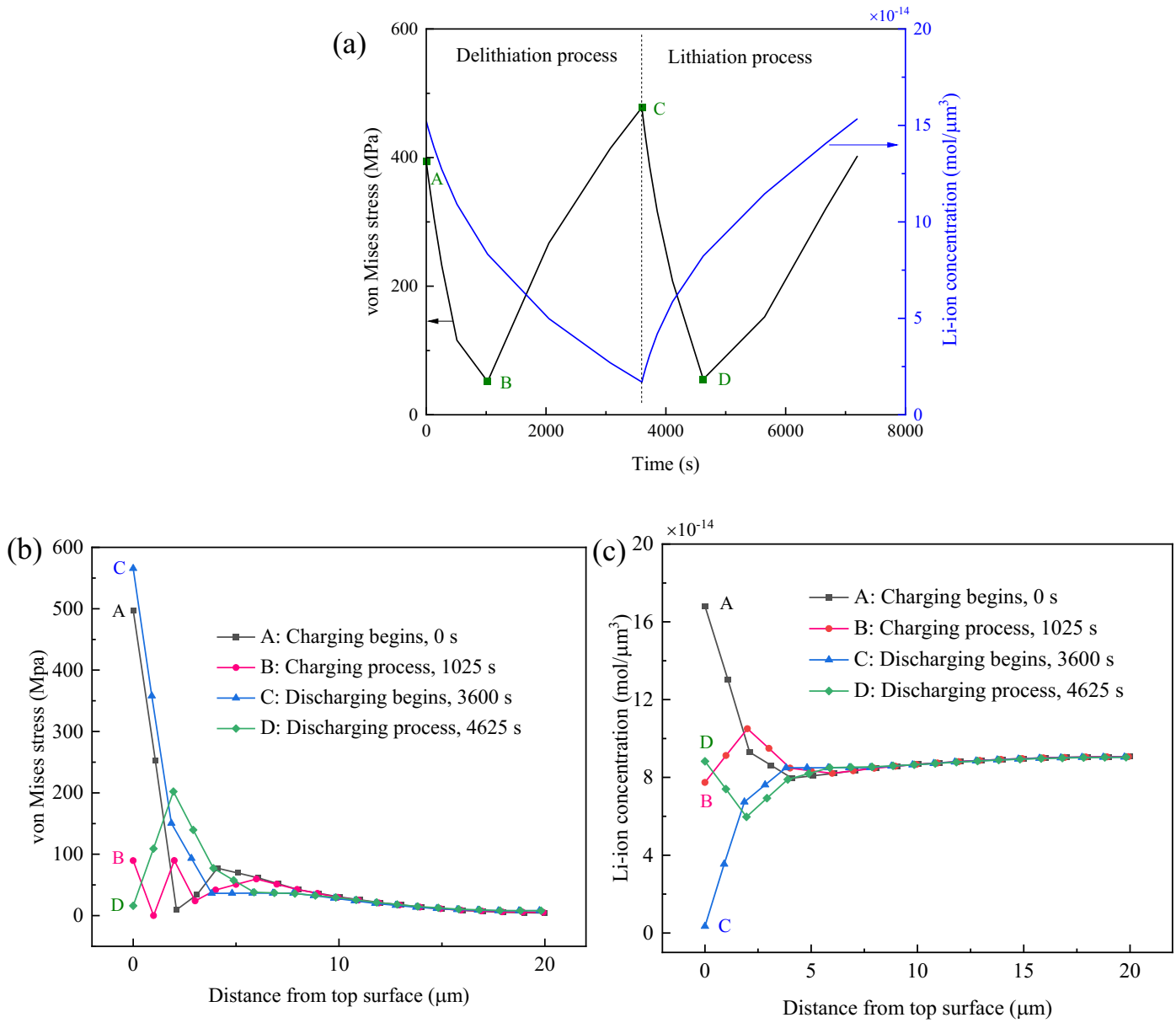

Figure 5 Diffusion-induced stress and corresponding lithium-ion concentration of

NMC active layer with $20 \mu \mathrm{m}$ in thickness with cycling duration (subjected to steady charging-discharging cycle at the charging rate of 1C) (a) Variation of von Mises stress and Li-ion concentration at top centre surface of cathode (b) Variation of von Mises stress along the thickness path at charging-discharging stage A, B, C and D (c) Variation of Li-ion concentration along the thickness path at A, B, C, D chargingdischarging stage 


\subsection{Evaluation of shakedown limit and ratcheting limit boundaries of NMC}

coating

For the shakedown limit and ratcheting limit boundaries of NMC cathode material with $20 \mu \mathrm{m}$ in thickness, the axes are expressed in non-dimensional variables, where $\Delta D / \Delta D_{0}$ is the normalized cyclic charging-discharging rate and $P / P_{0}$ is the normalized pressure as shown in Fig.6a. $\Delta D_{0}$ represents the cyclic diffusion-induced stress under the charging rate $1 \mathrm{C}$, while $P_{0}\left(P_{0}=19.15 \mathrm{MPa}\right)$ is the reference constant mechanical load applied on the NMC cathode of the coin cell equivalent to the pressure 6.2 $\mathrm{MPa}$ acting on the coin cell $(\mathrm{D}=20 \mathrm{~mm})$. Both $\Delta D_{0}$ and $P_{0}$ values are consistent with the experiment load conditions. It can be observed from Fig.6a that the normalized limit load is 5.95 , the normalized reverse plastic limit is 0.23 , and the ratcheting limit is 0.48 . The results indicate that the actual pressure limit for the NMC active layer is about $113.94 \mathrm{MPa}$, while the reverse plastic limit can be expressed as the charging rate $0.23 \mathrm{C}$. There are different failure modes under different load combinations, including shakedown region, reverse plastic region and ratcheting region. The shakedown boundary comprises of the reverse plasticity limit, with a part of the ratchet limit. The ratchet boundary shares its lower part with the shakedown boundary and approaches Y-axis with increasing $\Delta D_{0}$. For cyclic loading beyond the reverse plastic limit, a certain range of plastic deformation develops as a closed loop until it reaches the ratchet limit. When the cyclic loading on the NMC structure is within the ratcheting region, there is an accumulation of plastic strain in the structure, which 
eventually results in the structural collapse.

For the verification of the ratcheting boundary calculated by the LMM, the load points, i.e., $\mathrm{M}$ and $\mathrm{N}$ (Fig.6a), that are just below and above the calculated ratchet limit boundary are selected for further step-by-step analysis. The equivalent plastic strain history of the structure for the cyclic loading points $\mathrm{M}$ and $\mathrm{N}$ is depicted in Fig.6b. As expected, the step-by-step analysis result shows a reverse plasticity mechanism under the cyclic load case $\mathrm{N}$, where the maximum equivalent plastic strain increases slowly for the beginning cycles and settles into a closed loop for the remaining cycles. For load case $\mathrm{M}$, there is an overall increasing trend of the maximum equivalent plastic strain with cycle numbers, which indicates the ratcheting mechanism.

To further investigate the structural failure mechanism of the NMC cathode coating, the contour maps of effective strain increment for load case $\mathrm{O}$ (reverse plasticity) and load case $\mathrm{P}$ (ratcheting) evaluated by shakedown analysis, and the plastic strain range and effective strain increment for load case Q (ratcheting) provided by ratcheting analysis are presented in Fig.6c. It is worth noting that the ratcheting analysis consists of a DSCA procedure and an extended shakedown analysis. Taking load case Q as an example, the DSCA is first applied to calculate the plastic strain range and varying residual stress field caused by the cyclic load case $\mathrm{Q}_{1}$, then an extended shakedown analysis is performed to evaluate the capacity of the structure at the cyclic load case $\mathrm{Q}_{1}$ to withstand an additional pressure before ratcheting takes place, i.e. the load point Q becomes the ratchet limit. It is worth mentioning that the maximum plastic strain range of $5.44 \mathrm{e}-04$ is located at the top centre surface of the cathode, and it 
indicates the presence of reverse plasticity at the centre of the electrode. Moreover, both contours of effective strain increment caused by cyclic load points P and Q at the ratcheting boundary demonstrate that the ratcheting behaviour appears on the electrode edge due to the constraints on the bottom of NMC active layer.

(a)

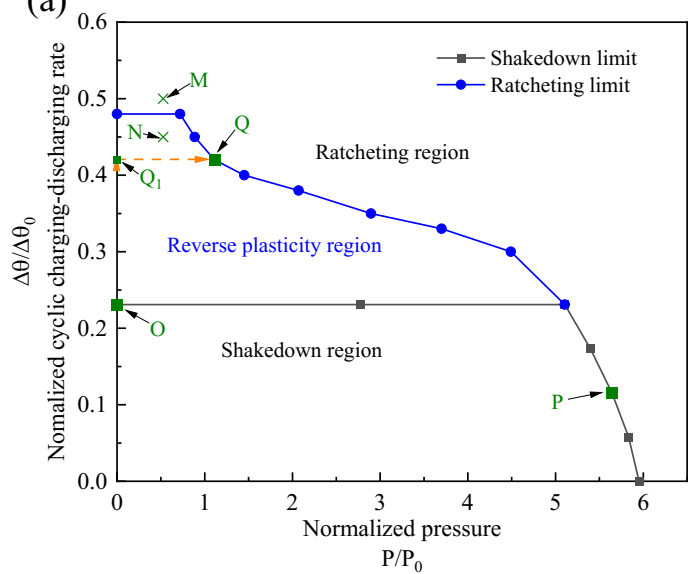

(c)

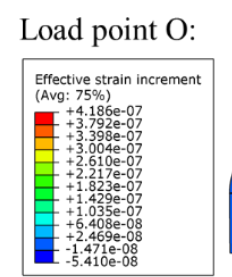

Load point Q:

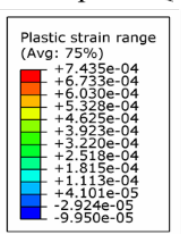

(b)

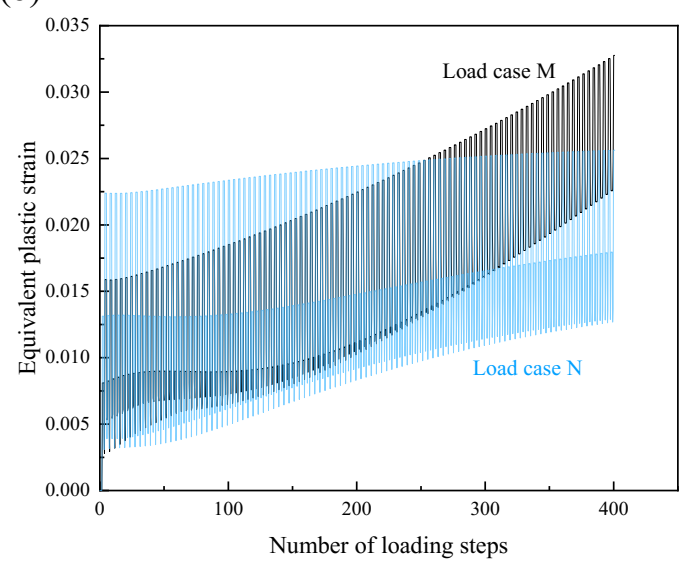

Figure 6 (a) Shakedown limit and ratcheting limit boundaries of NMC cathode material with $20 \mu \mathrm{m}$ in thickness, calculated by LMM, M, N, O, P, Q load points are marked for further analysis (b) Step-by-step analysis of load case M and N to verify the accuracy of the shakedown and ratcheting boundary (c) Contour map of effective stain increment for load case $\mathrm{O}$ and load case $\mathrm{P}$, the plastic strain range and effective stain increment for load case Q, while O, P, Q are at the shakedown limit and ratcheting limit boundaries 


\subsection{Effect of thickness for NMC coating shakedown and ratcheting limit boundaries}

To consider the thickness effect of the NMC coating, shakedown and ratcheting limit boundaries for NMC coating with thickness of $10 \mu \mathrm{m}$ and $30 \mu \mathrm{m}$ are also calculated using the LMM, and the results are shown in Fig.7. It can be observed that there is a similar overall trend of shakedown limit and ratcheting limit curves for NMC coating with thickness of $10 \mu \mathrm{m}, 20 \mu \mathrm{m}$ and $30 \mu \mathrm{m}$. The limit load of the NMC active layer decreases with the increase of thickness, while the values are relatively close. The slight differences of limit load between $10 \mu \mathrm{m}, 20 \mu \mathrm{m}$ and $30 \mu \mathrm{m}$ are due to the thinfilm structure of cathode material, whereby thinner coating can exhibit more obvious constraint effect. It is worth noting that both the reverse plastic limit and ratcheting limit increase with the increase of thickness, which indicates that thinner active layer can result in a more hazardous cathode when subjected to cyclic diffusion-induced stress.

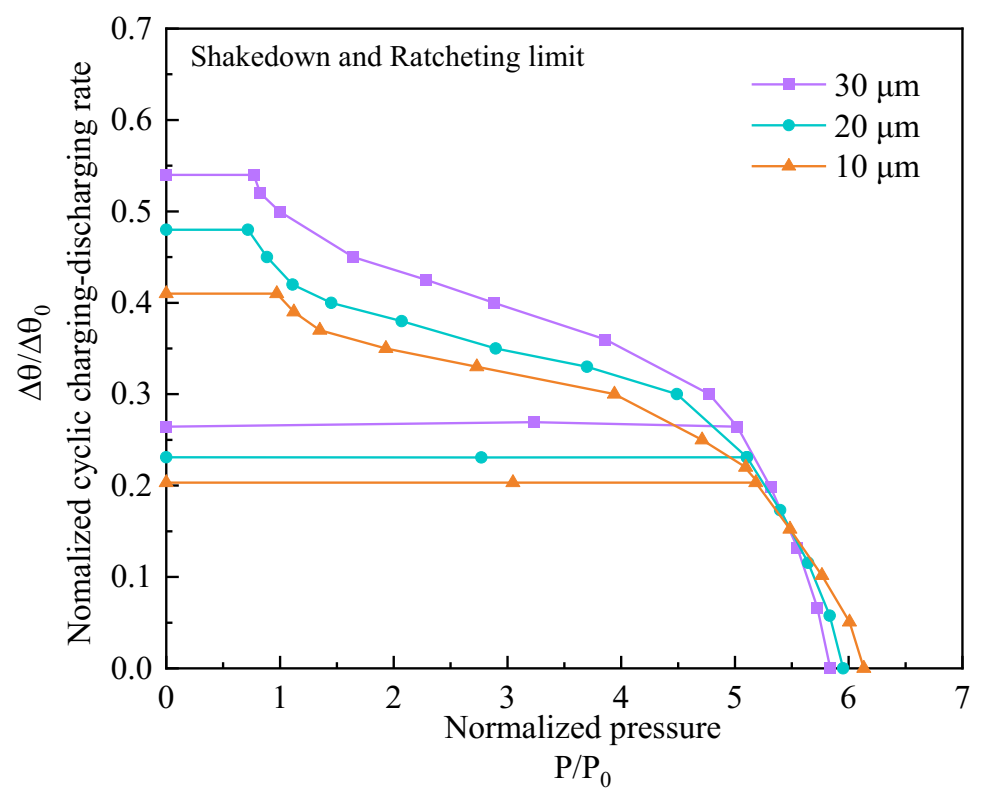

Figure 7 Shakedown limit and ratcheting limit curves of NMC cathode material with varying thickness $10 \mu \mathrm{m}, 20 \mu \mathrm{m}$ and $30 \mu \mathrm{m}$ 
Electrode thickness is known as an important parameter affecting the electrochemical performance of a cell[27, 28, 42-44]. The use of thick electrodes with high-loading density of active material is one of the most practical strategies to increase the specific energy density of lithium-ion battery, while taking advantage of the current electrode chemistry. With the increasing of the NMC coating thickness, the energy density of cathode is enhanced due to the reduction of inactive materials. However, there is a deteriorated cycling performance and a more severe capacity loss at higher rate for thicker NMC coating, due to the higher internal resistance. Therefore, a compromise should be made considering the effects of thickness on the mechanical failure and electrochemical performance of NMC coating.

\subsection{Low cycle fatigue life of NMC coating}

The number of cycles to failure from experimental observation indicates that it is a strain-controlled low cycle fatigue failure, where the number is normally less than $10^{4}$. Based on the Manson and Coffin relation[45], the relationship between plastic strain and fatigue life can be expressed as:

$$
\lg \frac{\Delta \varepsilon_{p}}{2}=c * \lg \left(2 N_{f}\right)+\lg \left(\varepsilon_{f}^{\prime}\right)
$$

where $\frac{\Delta \varepsilon_{p}}{2}$ is the plastic strain amplitude, $2 N_{f}$ is the number of reversals to failure, $\varepsilon_{f}^{\prime}$ is the fatigue ductility coefficient (an empirical constant), and c denotes the fatigue ductility exponent.

To better describe the fatigue life simpler and clearer, the following equation is applied for the further analysis:

$$
\lg \Delta \varepsilon_{p}=a * \lg \left(N_{f}\right)+b
$$


where $\mathrm{a}$ and $\mathrm{b}$ are fatigue constants.

For the strain-life curve showed in Fig.8, the variable $\Delta \varepsilon_{p}$ is calculated by the DSCA on NMC with a thickness of $20 \mu \mathrm{m}$ under the charging rate of $0.5 \mathrm{C}, 1 \mathrm{C}, 2 \mathrm{C}$ and 3C. $N_{f}$ is determined from the electrochemical cyclic test, where it can be expressed as the corresponding cycle number at which the capacity of the cell decreased to $80 \%$ of the initial capacity. The fitted parameters, $a=-2.44383$ and $b=4.4315$ are based on the data presented in Table 2 using the least squares linear regression. It is worth mentioning that the parameterized strain-life curve plotted in Fig.8, can be applied to predict the life of NMC cathode under other charging rates and to compare the degradation of the experimental capacity.

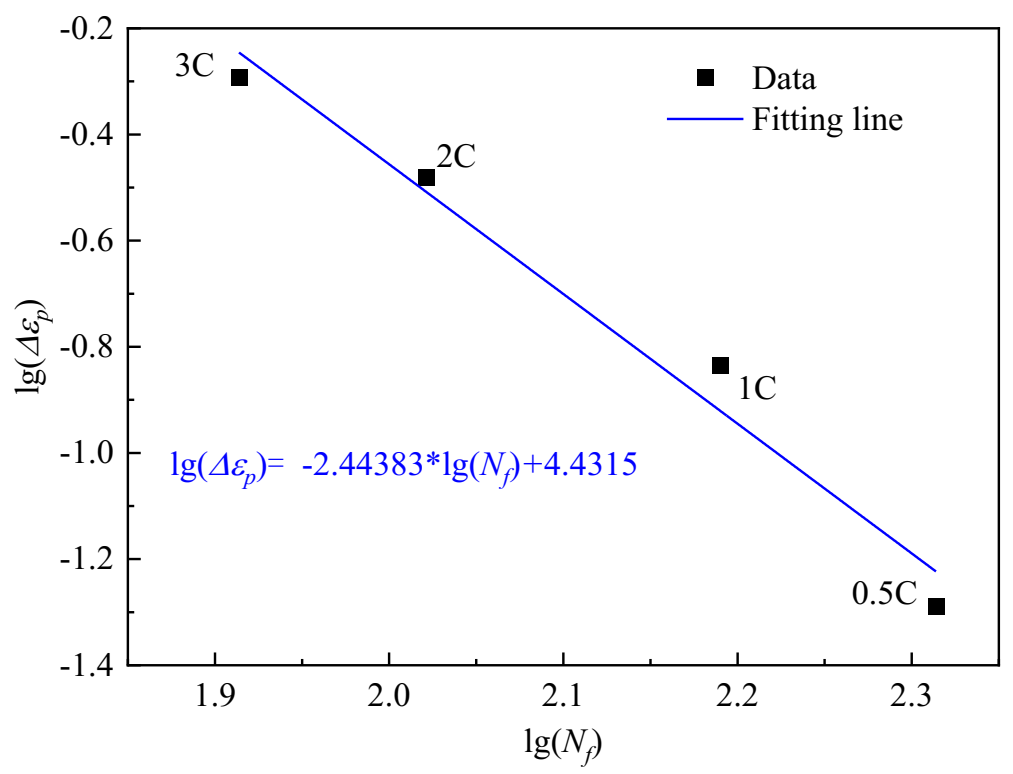

Figure 8 Strain-fatigue life curve of NMC cathode material with thickness of $20 \mu \mathrm{m}$ 
Table 2 Data collected from DSCA and charging-discharging tests for the strainlife curve

\begin{tabular}{ccc}
\hline Charging rate & $\Delta \varepsilon_{p}$ by DSCA & $N_{f}$ by tests \\
\hline $0.5 \mathrm{C}$ & 0.051344 & 206 \\
$1 \mathrm{C}$ & 0.145918 & 155 \\
$2 \mathrm{C}$ & 0.33045 & 105 \\
$3 \mathrm{C}$ & 0.510841 & 82 \\
\hline
\end{tabular}

\subsection{Cyclic plasticity behaviour of NMC coating subjected to charging-discharging} cycles

In this section, the cyclic plasticity behaviours of NMC coating of $20 \mu \mathrm{m}$ thickness are further investigated by both the numerical analysis and experimental test when it is subjected to a charging rate of $1 \mathrm{C}$ and a constant pressure of $19.15 \mathrm{MPa}$, which corresponds to the cyclic load point $(1,1)$ in Fig.6a. The experiment result of electrochemistry performance of cell at $1 \mathrm{C}$ shown in Fig.1d, indicates a steady decay of battery capacity and justifies the application of the DSCA. Figure 9a shows the contour of the plastic strain range and ratcheting strain of NMC cathode material under cyclic load point $(1,1)$. The ratcheting strain in this work is defined as a net accumulation of plastic strain over the steady state cycle. It is obvious that the corresponding load case $(1,1)$ in Fig.6a is located in the ratcheting region. It is indicated that there exists both fatigue and ratcheting under the load case $(1,1)$, while the maximum value of plastic strain range of 0.146 at all integration point is located at the 
centre of the structure and the maximum value of ratcheting strain $1.68 \mathrm{e}-02$ is located on the edge of cathode. The plastic strain and ratcheting strain are observed to be located mainly on top surface of the cathode structure. Furthermore, it can be seen clearly that the ratcheting strain value of $6.64 \mathrm{e}-05$ at the centre is much lower than the magnitude of plastic strain range 0.146 , so the ratcheting of the centre can be ignored in this case. The ratcheting strain and plastic strain range on the edge is $1.68 \mathrm{e}-02$ and $9.98 \mathrm{e}-02$ respectively, and both are greater than the ratcheting strain at the centre, indicating that the ratcheting mechanism of NMC coating mainly occurs on the edge under cyclic load point $(1,1)$. The plastic strain range against the distance from the top surface to the bottom of the cathode is plotted in Fig 9b, where the plastic strain range drops significantly near the top surface of the NMC coating. In general, the top centre surface of the cathode exhibits the fatigue failure, while the edge of the top surface shows ratcheting behaviour due to the accumulation of plastic strain. The result indicates that the crack initiation is tend to occur at the centre of the cathode, while the accumulation of plastic deformation increment on the edge of cathode coating will cause the incremental plastic collapse of the coating.

The ratcheting mechanism can also be observed after the cell chargingdischarging experiments (Fig.1d) by comparing the photographs of pristine NMC cathode and the cycled NMC cathode, as shown in Fig.9c. The active coating layer is subjected to the cyclic lithiation/delithiation at the charging rate of $1 \mathrm{C}$ and a constant pressure of $19.15 \mathrm{MPa}$, which suffers the accumulation of plastic deformation on the edge of the top surface, leading to incremental plastic collapse after a number of load 
cycles. While the lithium ions are inserted into and extracted out at the interface of the cathode and electrolyte. It can be clearly observed from the cycled NMC cathode that debonding of active coating layer from the $\mathrm{Al}$ current collector tends to occur on the edge of the cathode surface, which is consistent with that observed from the above numerical results.

(a)
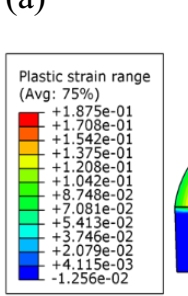

Fatigue at top centre

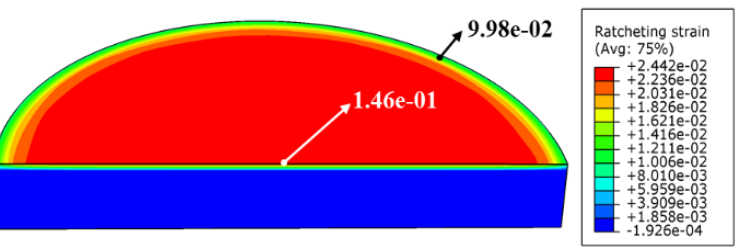

Racheting at top edge

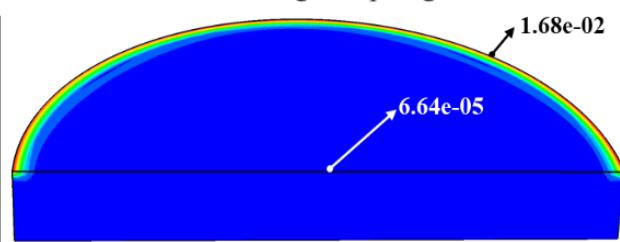

(b)

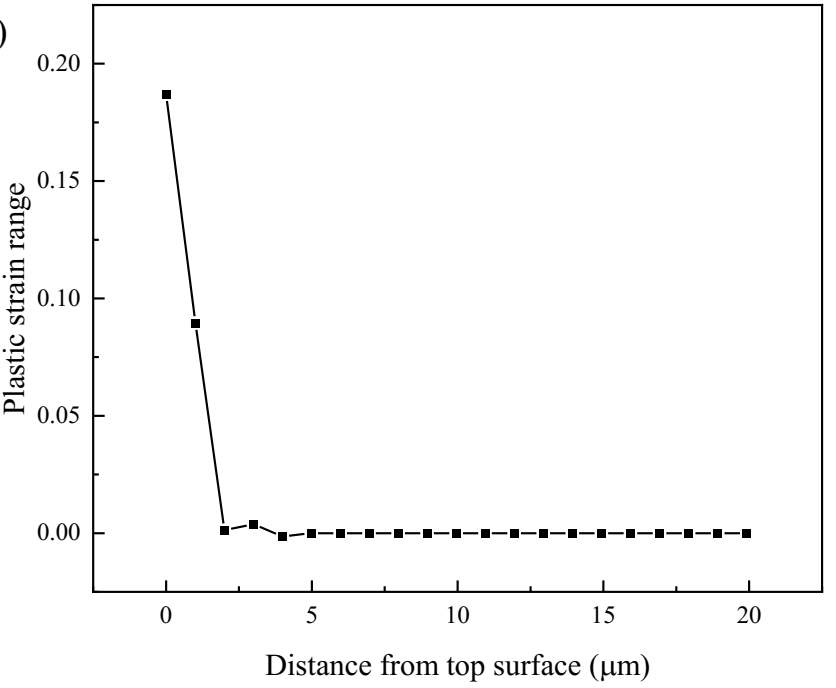

(c)
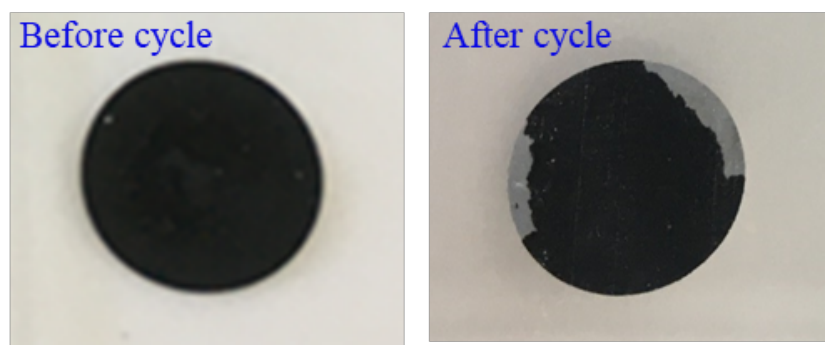

Figure 9 (a) Contour map of plastic strain range and ratcheting strain of NMC active layer of $20 \mu \mathrm{m}$ thickness for load point $(1,1)$ along path (as defined in Fig.A2) (b) Plastic strain range variation along the thickness direction from the top surface of the cathode material (c) NMC cathode before cyclic charging-discharging test (left) and 
after cyclic charging-discharging test (right)

To further study the fatigue mechanism indicated at the centre of the NMC structure under experimental condition aforementioned, the hysteresis loops are presented in Fig.10. Figure 10a and 10b represents the hysteresis loop of centre and edge for cyclic load point $(1,1)$ respectively, which are based on the DSCA calculation of selected integration points during a steady charging-discharging cycle. A, B, C, and D represent the charging-discharging stages depicted in the Fig.3a. It is noted that the ratcheting strain behaviour at the edge of NMC coating is significant, while the ratcheting strain at the centre is negligible. The result is due to the different material responses between the centre and edge of NMC coating during the loading period C-D, whereby material continues to yield at the centre but exhibits elastic-plastic unloading behaviour at the edge of NMC coating. It is worth noting that the plastic strain range shown in Fig.10 can be used to calculate the low cycle fatigue life as shown in equation (20). 

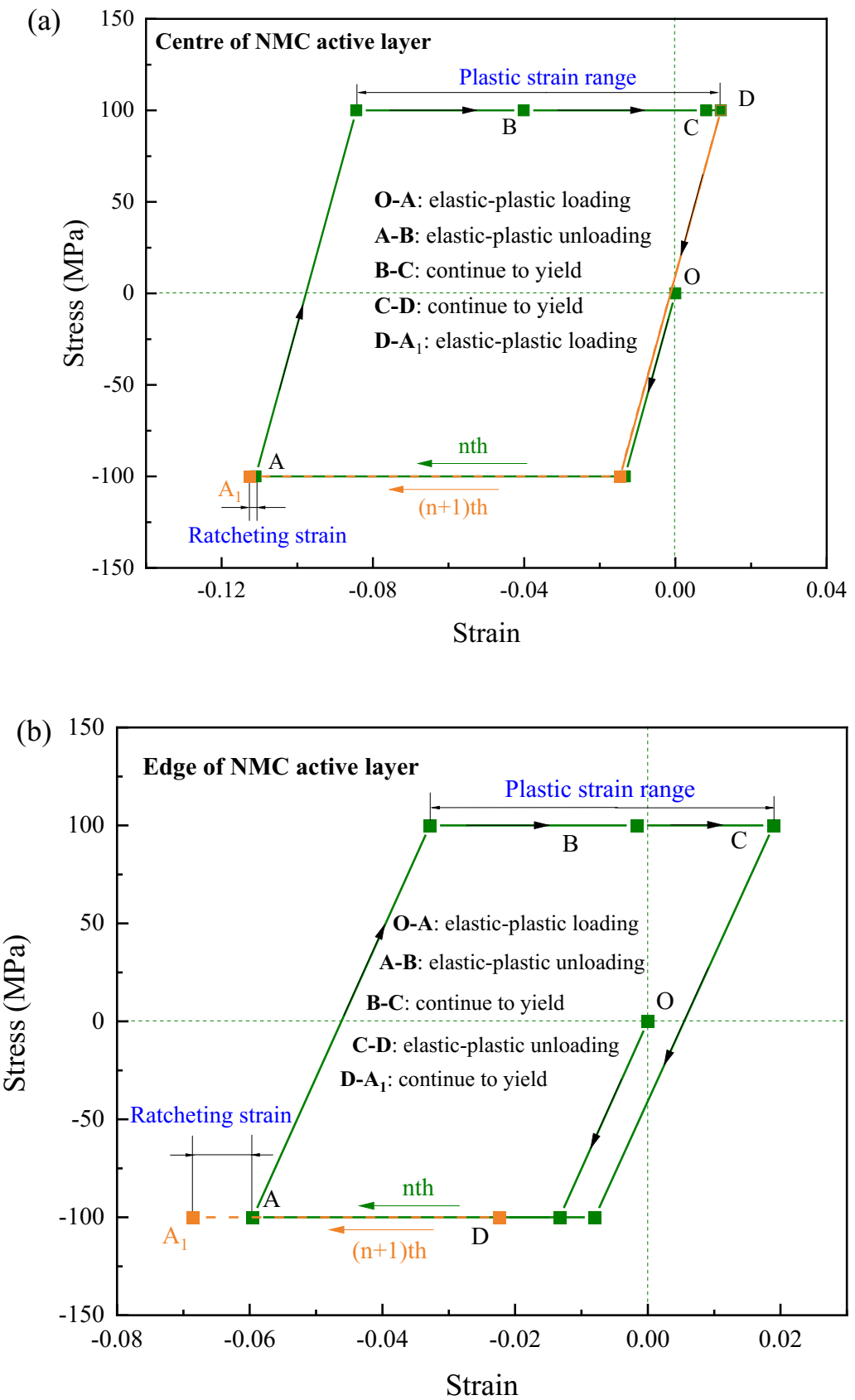

Figure 10 (a) hysteresis loop of the centre of NMC coating under cyclic load point $(1,1)$ and (b) hysteresis loop of the edge of NMC active layer under cyclic load point $(1,1)$ 


\section{Conclusions}

The cyclic plasticity behaviour and failure mechanism of NMC cathode coating are studied systematically based on the ABAQUS modelling, LMM numerical procedures and charging-discharging experiments. The results can be concluded as follows:

1) Under the cyclic diffusion-induced stress and constant mechanical load, the shakedown and ratcheting boundaries of NMC cathode coating with $20 \mu \mathrm{m}$ in thickness are obtained using the LMM and verified by step-by-step analysis. It is shown that typically a reverse plasticity mechanism occurs at the centre and ratcheting mechanism appears at the edge of NMC coating.

2) To study the effect of the thickness of NMC coating, shakedown and ratcheting limit curves of $\mathrm{NMC}$ coating with various thickness, i.e., $10 \mu \mathrm{m}, 20$ $\mu \mathrm{m}$ and $30 \mu \mathrm{m}$ are compared. As a result of thin NMC active layer, a slight difference between the limit loads, with a more obvious constraint effect on a thinner coating leading to a slightly higher limit load. The reverse plastic limit and ratcheting limit increase with the increase of thickness. As the active layer becomes thinner, the cathode becomes more hazardous when subjected to the cyclic diffusion-induced stress. A compromise should be made considering the effects of thickness on the mechanical failure and electrochemical performance of NMC coating.

3) Combining the experimental data collected from electrochemical experiments, strain-fatigue life curve is derived based on the DSCA analysis and fitted using 
the least squares linear regression method, which can be used in the prediction of life of NMC cathode under varying charging-discharging rates.

4) The cyclic plasticity behaviour of NMC coating of $20 \mu \mathrm{m}$ thickness subjected to a charging rate of $1 \mathrm{C}$ and a constant pressure of $19.15 \mathrm{MPa}$ are further investigated. Based on the numerical results, the accumulation of plastic deformation at the edge of cathode coating tends to result in a ratcheting mechanism, leading to an incremental plastic of the cathode, which is consistent with the experimental observation. While a low cycle fatigue tends to occur at the centre of NMC coating due to the larger plasticity range demonstrated in the derived hysteresis loops at the different locations.

\section{Acknowledgments}

The authors gratefully acknowledge the supports from the China Scholarship Council, Shanghai Automobile Industry Science and Technology Development Foundation (1801), National Natural Science Foundation of China (51828501), the Higher Education Discipline Innovation Project (111 Project) under the funding code B13020, University of Strathclyde and East China University of Science and Technology during the course of this work.

\section{References}

[1] C. Hendricks, N. Williard, S. Mathew, M. Pecht, A failure modes, mechanisms, and effects analysis (FMMEA) of lithium-ion batteries, Journal of Power Sources 297 (2015) 113-120.

[2] R. Xu, Y. Yang, F. Yin, P. Liu, P. Cloetens, Y. Liu, F. Lin, K. Zhao, Heterogeneous damage in Li-ion batteries: Experimental analysis and theoretical modeling, Journal of the Mechanics and Physics of 
Solids 129 (2019) 160-183.

[3] S.P.V. Nadimpalli, V.A. Sethuraman, D.P. Abraham, A.F. Bower, P.R. Guduru, Stress Evolution in Lithium-Ion Composite Electrodes during Electrochemical Cycling and Resulting Internal Pressures on the Cell Casing, Journal of The Electrochemical Society 162 (2015) A2656-A2663.

[4] S. Prussin, Generation and Distribution of Dislocations by Solute Diffusion, Journal of Applied Physics 32 (1961) 1876-1881.

[5] R.A. Huggins, W.D. Nix, Decrepitation model for capacity loss during cycling of alloys in rechargeable electrochemical systems, Ionics 6 (2000) 57-63.

[6] J. Christensen, J. Newman, Stress generation and fracture in lithium insertion materials, Journal of Solid State Electrochemistry 10 (2006) 293-319.

[7] X. Zhang, W. Shyy, A. Marie Sastry, Numerical Simulation of Intercalation-Induced Stress in Li-Ion Battery Electrode Particles, Journal of The Electrochemical Society 154 (2007) A910.

[8] T.K. Bhandakkar, H. Gao, Cohesive modeling of crack nucleation under diffusion induced stresses in a thin strip: Implications on the critical size for flaw tolerant battery electrodes, International Journal of Solids and Structures 47 (2010) 1424-1434.

[9] H. Haftbaradaran, H. Gao, W. Curtin, A Surface Locking Instability for Atomic Intercalation Into a Solid Electrode, Applied Physics Letters 96 (2010) 091909-091909.

[10] T. Takamura, S. Ohara, M. Uehara, J. Suzuki, K. Sekine, A vacuum deposited Si film having a Li extraction capacity over $2000 \mathrm{mAh} / \mathrm{g}$ with a long cycle life, Journal of Power Sources 129 (2004) 96100 .

[11] K. Zhao, G.A. Tritsaris, M. Pharr, W.L. Wang, O. Okeke, Z. Suo, J.J. Vlassak, E. Kaxiras, Reactive Flow in Silicon Electrodes Assisted by the Insertion of Lithium, Nano Letters 12 (2012) 4397-4403.

[12] X.H. Liu, J.Y. Huang, In situ TEM electrochemistry of anode materials in lithium ion batteries, Energy \& Environmental Science 4 (2011) 3844.

[13] Z. Liu, J. Zhou, B. Chen, J. Zhu, Interaction between dislocation mechanics on diffusion induced stress and electrochemical reaction in a spherical lithium ion battery electrode, RSC Advances 5 (2015) 74835-74843.

[14] V.A. Sethuraman, V. Srinivasan, A.F. Bower, P.R. Guduru, In Situ Measurements of Stress-Potential Coupling in Lithiated Silicon, Journal of The Electrochemical Society 157 (2010) A1253.

[15] V.A. Sethuraman, M.J. Chon, M. Shimshak, V. Srinivasan, P.R. Guduru, In situ measurements of stress evolution in silicon thin films during electrochemical lithiation and delithiation, Journal of Power Sources 195 (2010) 5062-5066.

[16] L. Brassart, K. Zhao, Z. Suo, Cyclic plasticity and shakedown in high-capacity electrodes of lithiumion batteries, International Journal of Solids and Structures 50 (2013) 1120-1129.

[17] Z. Jia, T. Li, Failure mechanics of a wrinkling thin film anode on a substrate under cyclic charging and discharging, Extreme Mechanics Letters 8 (2016) 273-282.

[18] K. Guo, W. Zhang, B.W. Sheldon, H. Gao, Concentration dependent properties lead to plastic ratcheting in thin island electrodes on substrate under cyclic charging and discharging, Acta Materialia 164 (2019) 261-271.

[19] Y. Li, J. Zhang, K. Zhang, B. Zheng, F. Yang, A defect-based viscoplastic model for large-deformed thin film electrode of lithium-ion battery, International Journal of Plasticity 115 (2019) 293-306.

[20] W. Li, B. Song, A. Manthiram, High-voltage positive electrode materials for lithium-ion batteries, Chem Soc Rev 46 (2017) 3006-3059.

[21] Z. Ma, H. Chen, Y. Liu, F.-Z. Xuan, A direct approach to the evaluation of structural shakedown 
limit considering limited kinematic hardening and non-isothermal effect, European Journal of Mechanics - A/Solids 79 (2019) 103877.

[22] H. Chen, A. Ponter, Shakedown and limit analyses for 3-D structures using the linear matching method, International Journal of Pressure Vessels and Piping 78 (2001) 443-451.

[23] H. Chen, A.R.S. Ponter, A Direct Method on the Evaluation of Ratchet Limit, Journal of Pressure Vessel Technology 132 (2010).

[24] M. Lytwyn, H.F. Chen, A.R.S. Ponter, A generalised method for ratchet analysis of structures undergoing arbitrary thermo-mechanical load histories, International Journal for Numerical Methods in Engineering 104 (2015) 104-124.

[25] H. Chen, A.R.S. Ponter, A method for the evaluation of a ratchet limit and the amplitude of plastic strain for bodies subjected to cyclic loading, European Journal of Mechanics - A/Solids 20 (2001) 555571.

[26] A.R.S. Ponter, H. Chen, A minimum theorem for cyclic load in excess of shakedown, with application to the evaluation of a ratchet limit, European Journal of Mechanics - A/Solids 20 (2001) 539553.

[27] K.-Y. Park, J.-W. Park, W.M. Seong, K. Yoon, T.-H. Hwang, K.-H. Ko, J.-H. Han, Y. Jaedong, K. Kang, Understanding capacity fading mechanism of thick electrodes for lithium-ion rechargeable batteries, Journal of Power Sources 468 (2020) 228369.

[28] B.S. Lee, Z. Wu, V. Petrova, X. Xing, H.D. Lim, H. Liu, P. Liu, Analysis of rate-limiting factors in thick electrodes for electric vehicle applications, Journal of the Electrochemical Society 165 (2018) A525-A533.

[29] ABAQUS, ABAQUS/CAE user's guide, Version 6.14, Dassault Systèmes Simulia Corp., Providence, RI, USA2014.

[30] R. Grantab, V.B. Shenoy, Location- and Orientation-Dependent Progressive Crack Propagation in Cylindrical Graphite Electrode Particles, Journal of The Electrochemical Society 158 (2011) A948.

[31] X. Zhu, Y. Chen, H. Chen, W. Luan, The diffusion induced stress and cracking behaviour of primary particle for Li-ion battery electrode, International Journal of Mechanical Sciences 178 (2020) 105608.

[32] W.T. Koiter, General Theorems for Elastic-plastic Solids, North-Holland1960.

[33] J. Zhu, X. Zhang, H. Luo, E. Sahraei, Investigation of the deformation mechanisms of lithium-ion battery components using in-situ micro tests, Applied Energy 224 (2018) 251-266.

[34] A. Paolone, R. Cantelli, G. Rousse, C. Masquelier, The charge order transition and elastic/anelastic properties of LiMn2O4, Journal of Physics: Condensed Matter 15 (2003) 457-465.

[35] A. Verma, K. Smith, S. Santhanagopalan, D. Abraham, K.P. Yao, P.P. Mukherjee, Galvanostatic Intermittent Titration and Performance Based Analysis of LiNi0.5Co0.2Mn0.3O2Cathode, Journal of The Electrochemical Society 164 (2017) A3380-A3392.

[36] O. Dolotko, A. Senyshyn, M.J. Mühlbauer, K. Nikolowski, H. Ehrenberg, Understanding structural changes in NMC Li-ion cells by in situ neutron diffraction, Journal of Power Sources 255 (2014) 197203.

[37] X.H. Liu, L. Zhong, S. Huang, S.X. Mao, T. Zhu, J.Y. Huang, Size-Dependent Fracture of Silicon Nanoparticles During Lithiation, ACS Nano 6 (2012) 1522-1531.

[38] G. Singh, T.K. Bhandakkar, Analytical investigation of binder's role on the diffusion induced stresses in Lithium ion battery through a representative system of spherical isolated electrode particle enclosed by binder, Journal of the Electrochemical Society 164 (2017) A608-A621.

[39] A. Sarkar, P. Shrotriya, A. Chandra, Simulation-driven Selection of Electrode Materials Based on 
Mechanical Performance for Lithium-Ion Battery, Materials (Basel) 12 (2019).

[40] X. Zhu, H. Chen, W. Luan, On the study of cyclic plasticity behaviour of primary electrode particle for lithium-ion battery, European Journal of Mechanics - A/Solids 86 (2021) 104175.

[41] C. Zhang, J. Xu, L. Cao, Z. Wu, S. Santhanagopalan, Constitutive behavior and progressive mechanical failure of electrodes in lithium-ion batteries, Journal of Power Sources 357 (2017) 126-137. [42] H. Zheng, J. Li, X. Song, G. Liu, V.S. Battaglia, A comprehensive understanding of electrode thickness effects on the electrochemical performances of Li-ion battery cathodes, Electrochimica Acta 71 (2012) 258-265.

[43] J. Jeong, H. Lee, J. Choi, M.-H. Ryou, Y.M. Lee, Effect of LiFePO 4 cathode density and thickness on electrochemical performance of lithium metal polymer batteries prepared by in situ thermal polymerization, Electrochimica Acta 154 (2015) 149-156.

[44] J. Liu, Z. Bao, Y. Cui, E.J. Dufek, J.B. Goodenough, P. Khalifah, Q. Li, B.Y. Liaw, P. Liu, A. Manthiram, Y.S. Meng, V.R. Subramanian, M.F. Toney, V.V. Viswanathan, M.S. Whittingham, J. Xiao, W. Xu, J. Yang, X.-Q. Yang, J.-G. Zhang, Pathways for practical high-energy long-cycling lithium metal batteries, Nature Energy 4 (2019) 180-186.

[45] S.S. Manson, Fatigue: A complex subject—Some simple approximations, Experimental Mechanics 5 (1965) 193-226. 